\title{
Let the Sun shine
}

\author{
There is more than enough power available from the Sun to satisfy the world's needs, so why \\ are we not rushing to exploit it?
}

The entire planet's yearly power needs could be provided by harnessing the solar energy that falls on its surface over the course of just one hour. The total electricity needs of the United States in 2003 could have been provided by covering an area of desert with just $100 \mathrm{~km} \times 100 \mathrm{~km}$ of solar panels operating at $15 \%$ power conversion efficiency ${ }^{1}$.

Figures like these convince many scientists that it is foolish to ignore solar power in future energy policies. Yet the interest of some governments and consumer markets does not match the enthusiasm of scientists. Indeed, just $0.1 \%$ of energy worldwide is currently provided by solar power. At the July 2008 G8 summit held in Japan - the world's biggest producer of solar cells - the consensus was to promote and support nuclear power, biofuels, and carbon capture and storage. Renewables were 'recognized' only in passing, and no specific mention was made of solar power ${ }^{2}$.

Frustrated by the lack of backing for photovoltaics, a group of more than 250 researchers lead by Daniel Lincot, president of the 2008 European Photovoltaic Solar Energy Conference, and CNRS researcher at Ecole Nationale Supérieure de Chimie de Paris, have put together the 'Valencia call. The call appeals for an accelerated worldwide deployment of photovoltaics through international collaborations and policy-level support ${ }^{3}$. Lincot says that solar power "has to be considered as a key solution at the highest political and decision-maker levels." He explains that the Valencia call asks "for increased support - financial, laws, regulations; and ambitions - fixed objectives for accelerating renewable energies implementation" from governments across the world.

The Solar Mediterranean Plan, an initiative by which solar power produced in southern countries could be shared by the rest of Europe to maximize generation efficiency

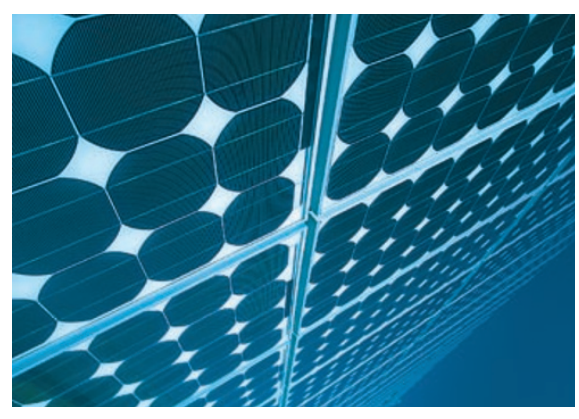

is still a long way from the US Department of Energy's cost goal of just $\$ 0.33$ per watt, although rising oil prices may make higher solar prices more acceptable.

The latest generation of cells are where immediate investment could make a dramatic difference to the time it takes for academic research to reach the marketplace. Organic materials, often used in conjunction with nanomaterials or absorbing dyes to maximize efficiency, could provide flexible, cheap cells. Although efficiencies are moderate compared with silicon cells, this is in the sunniest countries, is one embodiment of the collaboration ideals of the Valencia call.

With all of this support from scientists, extensive research and vast amounts of energy waiting to be exploited, what's stopping solar energy from being hailed as the saviour of our planet? Sadly, the answer must lie with costs: at \$4 per watt (ref. 1), solar energy is too expensive to appeal when we're currently paying only a few cents.

Some governments, such as those of Japan, Germany, France and Spain, are acting to tackle this problem with initiatives such as feed-in tariffs. Here, energy companies are obliged to purchase renewable energy at a higher-than-market price, with the additional cost spread across all consumers. This higher price encourages solar generation at all scales; for instance, Germany adopted a feed-in tariff strategy in 2004, and in 2006 alone, 380,000 domestic solar units were installed, taking them to a total of 1.6 million.

It is in driving down costs that new technologies beyond first-generation crystalline silicon cells will have an important role. Solar cells based on amorphous silicon and other inorganics such as cadmium telluride are now maturing, and use thinner, and therefore cheaper, films of active material. Indeed, a cadmium telluride cell with a manufacturing cost of just $\$ 1.25$ per watt has recently been reported ${ }^{4}$. This less important when the manufacturing costs are kept much lower; the price per watt is still favourable. Alternatively, the concentration of solar energy can drastically reduce the amount of active materials needed - and along with it the cost $t^{5}$. Indeed, an innovative approach to solar concentration is presented in this issue: John Rogers and colleagues ${ }^{6}$ use transfer printing to create microscale photovoltaic cells of silicon that are mechanically flexible and therefore combine lightweight and cost-efficient design with the high photovoltaic efficiencies of silicon.

It is an ideal time for governments to provide subsidies and other support for solar technology that could make a positive difference to their countries' long-term balance of energy and emissions. The photovoltaics market is already growing at $40 \%$ a year, but greater financial and political encouragement for both industry and consumers to invest in the technology could speed both its improvement and adoption on a wider scale.

\footnotetext{
References

1. Ginley, D., Green, M. A. \& Collins, R. Mater. Res. Soc. Bull. 33, 355-364 (2008).

2. http://www.whitehouse.gov/news/releases/2008/07/ 20080708-3.html

3. http://www.photovoltaic-conference.com/357.0.html

4. http://investor.firstsolar.com/releasedetail.cfm?ReleaseID $=229824$

5. Barnham, K. W. J., Mazzer, M. \& Clive, B. Nature Mater. 5, 161-164 (2006).

6. Yoon, J. et al. Nature Mater. 7, 907-915 (2008).
} 
Do we now understand entangled unlinked rings? We are closer, to be sure, but enough questions still remain to require more intense scrutiny. It is hard to make very highly entangled polystyrenes because of the bulkiness of the monomer: experiments on the considerably skinnier polybutadiene will test these ideas to the limit. Rheological probes are overdue, as are structural ones such as neutron scattering, and the rich seam of nonlinear response has yet to be mined. Furthermore, the topic has implications beyond finessing of our understanding of entangled polymer dynamics. Some DNA separation techniques rely on ring-polymer dynamics. And in a strange leap of concepts from one field of physics to another, some astrophysical media interlaced with loops of magnetic field may behave just like viscoelastic fluids supporting ring-polymers ${ }^{6}$. From fundamentals of entanglements to the fluid dynamics of the Sun, rings retain a powerful fascination.
Whether uncovering their secrets proves as endless a story as the rings themselves remains to be seen.

\section{References}

1. Doi, M. \& Edwards, S. F. The Theory of Polymer Dynamics (Oxford Univ. Press, 1986)

2. McLeish, T. C. B. Adv. Phys. 51, 1379-1527 (2002)

3. Kapnistos, M. et al. Nature Mater. 7, 997-1002 (2008).

4. Obhukov, S. P., Rubinstein, M. \& Duke, T. Phys. Rev. Lett. 73, 1263-1266 (1994)

5. Cates, M. E. \& Deutsch, J. M. J. Phys. (Paris) 47, 2121-2128 (1986).

6. Longcope, D. W., McLeish, T. C. B. \& Fisher, G. H. Astrophys. J. 599, 661-674 (2003).

\section{Let the Sun shine}

Nature Materials 7, 825 (2008); published online: 27 October 2008; corrected after print: 4 November 2008.

In the version of this Editorial originally published online, the second sentence of the first paragraph should have referred to 'electricity' needs, and to a total area of ' $100 \mathrm{~km} \times 100 \mathrm{~km}$ ', not '100 square kilometres'. The sentence has been corrected in the HTML and PDF versions of the Editorial. 